\title{
Results from Poland's 2018 Report Card on Physical Activity for Children and Youth
}

\author{
Paweł Zembura, Agata Korcz, Elżbieta Cieśla, Aleksandra Gołdys, and Hanna Nałęcz
}

\section{Introduction}

Recent nationwide studies regarding physical activity (PA) in Poland suggest that a small proportion of children and youth are meeting the recommended level of $\geq 60$ minutes of moderate-tovigorous intensity PA (MVPA) per day. ${ }^{1,2}$ Further, additional evidence regarding health-related behaviors linked with PA, such as screen time and environmental factors determining PA of children and youth, were assessed to be far from satisfactory. ${ }^{3}$ In this paper, we reviewed the best available evidence regarding PA in Polish children and youth to grade indicators describing the complex PA environment.

\section{Methods}

The 2018 Polish Report Card (Figure 1) included 10 core PA indicators used in the Global Matrix 3.0 (Overall Physical Activity, Organized Sport Participation, Active Play, Active Transportation, Sedentary Behavior, Physical Fitness, Family and Peers, School, Community and Environment, Government). Each indicator was accompanied by at least one assessment benchmark. Changes to the grading process have been made since the Global Matrix 2.0; therefore, differences in grades in reference to Poland's 2016 Report Card do not represent actual trends.

In the 2018 Polish Report Card, we combined data from the multiple sources. First, the Research Team (RT) conducted systematic reviews to identify data sources pertaining to each of the indicators, which were later assessed using the modified Downs and Black checklist. ${ }^{4}$ The separate cut-off points have been established in reference to each indicator based on the amount and quality of the available data. All data sources were published within the last 5 years (since 2013), with the exception of the Physical Fitness indicator. The most informative sources of data were two cross-national surveys conducted in 2013/2014: Health Behaviour of School Youth in Poland ${ }^{1}$ and the Physical Activity of School Children Aged 9-17.2

\section{Results and Discussion}

The 2018 Polish Report Card is the second assessment of children and youth PA in the Active Healthy Kids Global Alliance project, following the Global Matrix 2.0 in 2016. The grades for each core PA indicator are summarized in Table 1, with a brief discussion and rationale provided.
The majority of the grades remain the same in 2018 when compared to the Poland's Report Card in 2016 and little has changed in terms of informative data sources regarding PA since this time. The current Report Card presents the Physical Fitness indicator for the very first time. The RT was able to grade each indicator except for the Active Play, although several other research gaps were revealed in the process. First, in this analysis we based our grades on self-reported data, what applied even to the core indicators such as overall PA and sedentary behaviour. Another important limitation was that RT was not able to identify nearly any data sources regarding children younger than 10 years old. For that reason this Report Card refers mainly to youth and does not present a general picture of children and youth PA in Poland.

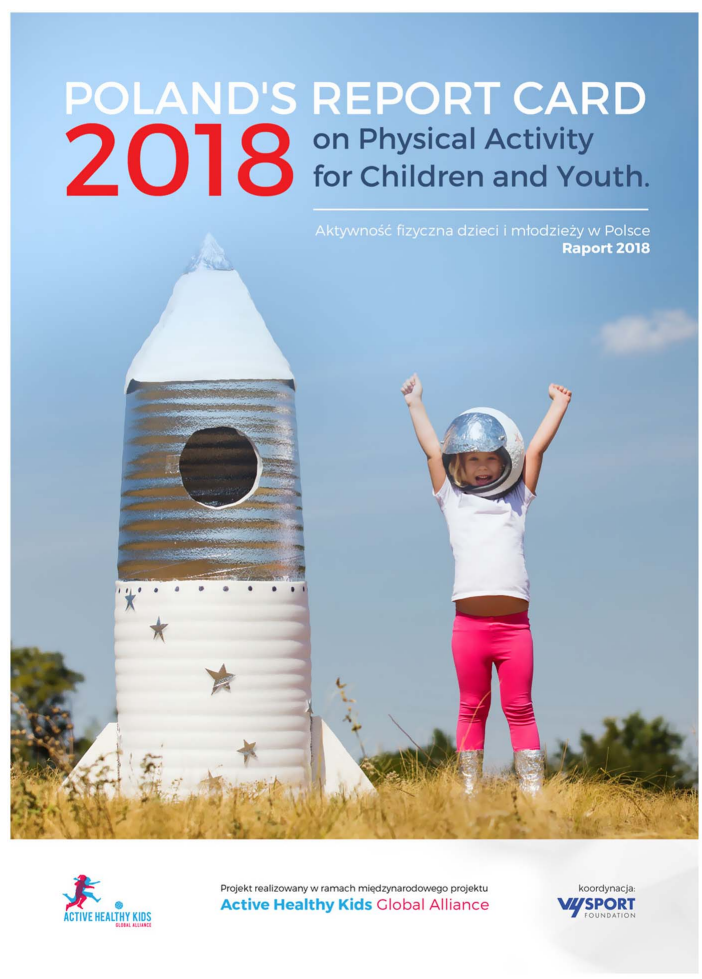

Figure 1 - Poland's 2018 Report Card cover.

Zembura and Gołdys are with the Social Challenges Unit at Robert B. Zajonc Institute of Social Science, University of Warsaw, Warsaw, Poland. Korcz is with Poznan University of Physical Education, Poznan, Poland. Cieśla is with the Faculty of Medical and Health Sciences, Jan Kochanowski University, Kielce, Poland. Nałęcz is with the Institute of Mother and Child, Warsaw, Poland. Zembura (pzembura@uw.edu.pl) is the corresponding author. 
Table 1 Grades and Rationales for Poland's 2018 Report Card

\begin{tabular}{|c|c|c|}
\hline Indicator & Grade & Rationale \\
\hline $\begin{array}{l}\text { Overall Physical } \\
\text { Activity }\end{array}$ & D- & $\begin{array}{l}24.2 \% \text { of } 11-\text { to } 15 \text {-year-olds met } 1 \text { hour of MVPA per day in the cross-sectional study }{ }^{1} \\
21.5 \% \text { of } 10 \text { - to } 17 \text {-year-olds met the recommendation in the other cross-sectional study }{ }^{2}\end{array}$ \\
\hline $\begin{array}{l}\text { Organized Sport } \\
\text { Participation }\end{array}$ & $\mathrm{D}$ & $\begin{array}{l}\text { 18.9\% of children and youth aged 10-17 participated in organized club sport outside of school at least once a week } \\
27.2 \% \text { took part in private lessons related to PA (such as tennis, karate or judo), at least once per week } \\
30.6 \% \text { participated in "other" unorganized or organized activities related to PA, at least once per week } \\
50.4 \% \text { of adolescents attending lower-secondary schools participated in some kind of organized sport-for-all } \\
\text { activities }\end{array}$ \\
\hline
\end{tabular}

Active Play INC $\quad 53.9 \%$ of lower-secondary school adolescents (between the ages of 12/13 and 15/16) participated in unorganized PA such as cycling, football and swimming at least once per week ${ }^{5}$

Active Transportation $\quad \mathrm{C} \quad 47.4 \%$ of 10- to 17-year-olds in Poland reported walking to school and 52.3\% walking from school 5.5\% and 5.2\% travel to and from school by bicycle, respectively ${ }^{2}$

$41 \%$ and $36 \%$ of lower-secondary and upper-secondary school students (between the ages of 15/16 and 18/19) mainly walk to school while, $5 \%$ and $3 \%$ of the groups commute by bicycle 6

Physical Fitness $\quad$ C-

C- $\quad$ Average tests scores were counted for each fitness test results (sit-and-reach, handgrip strength, standing broad jump, sit-ups, relative peak oxygen uptake, $10 \times 5 \mathrm{~m}$ agility shuttle run, $20 \mathrm{~m}$ shuttle run test (laps) and plate tapping test) separately for each age group of boys and girls using means or medians reported in the available data. The obtained average results were referred to the centile values provided in the summary paper (for each age group and gender). ${ }^{7}$ We averaged those centile values for each physical fitness test to obtain a mean score for the respective test. The overall score was made up by averaging the mean scores of the eight fitness tests. Dobosz et al, ${ }^{8}$ study was the main source of data.

Sedentary Behaviours D $\quad 40 \%$ of 11 - to 15-year-olds reported watching TV and films, $65.9 \%$ playing computer games, and $45.2 \%$ reported performing other computer-based activites ${ }^{1}$

$49 \%$ of lower-secondary and $44 \%$ of upper-secondary school students declared spending $\leq 2$ hours watching TV or on computer, daily $636 \%$ of 10 - to 15 -year-olds met the recommendation of $\leq 2$ hours of recreational screen time per day ${ }^{9}$

Family and Peers $\quad$ C- $\quad 51.6 \%$ of 12- to 18-year-olds reported that parents always or almost always give support to their participation in PA materially (by providing resources), $64.5 \%$ consider themselves enabled to participate in PA, $41.4 \%$ get emotional support, $17.3 \%$ receive support in planning activities ${ }^{10}$

$15.1 \%$ of mothers and $24 \%$ of fathers regularly participate in sport or are physically active at least once per week according to 10 - to 17 -year-olds ${ }^{2}$

$21.2 \%$ of 13 - to 16-year-olds declared being regularly physically active with their father, $17.9 \%$ with their mother, and $42.8 \%$ with their siblings ${ }^{2}$

$20 \%$ of 12 - to 18 -year-olds declared being physically active with their father and $18.5 \%$ with their mothers ${ }^{10}$

School B $\quad 73.8 \%$ of 10- to 17-year-olds reported participating in all or nearly all physical education (PE) lessons ${ }^{2}$ $87 \%$ of primary, $96 \%$ of lower-secondary and $89 \%$ of upper-secondary schools students participate in PE lessons The amount of compulsory PE in Poland equals three 45 minutes lessons per week in grades 1-3 of primary school, 4 such lessons in grades 4-8 of primary school and 3 lessons in secondary school

Community and $\quad$ C 29\% of 10-to 17-year-olds perceive their neighbourhood environment encourages PA while 48.3\% consider it to be Environment neutral ${ }^{2}$

$19 \%$ of respondents from Poland totally agree and $49 \%$ tend to agree that their local area offers them many opportunities to be physically active

$16 \%$ totally agree and $47 \%$ tend to agree that clubs and local providers offer many opportunities to be physically active

$11 \%$ totally disagree and $22 \%$ tend to disagree with a statement that their local authority does not make enough in relation to $\mathrm{PA}^{11}$

Government $\quad$ C $+\quad$ In the last two years, two large-scale sport-for-all programs named Club and School Sports Club (both are investments in small and medium local sports clubs) have been implemented

A primary governmental funding initiative for sport development in children and adolescents (Physical Culture Development Fund) increased by $28 \%$ in 2018 in comparison to an annual increase of $9.4 \%$ in 2017, 6\% in 2016 and $14.1 \%$ in 2015

Through Good Management Codex the Ministry of Sport pressured national sports federations to get involved in sport-for-all

Note: The principal sources of data were italicized.

\section{Conclusion}

Despite the promising PA climate in Poland, as suggested by strong grades allocated to the School and Government indictors, the proportion of children and youth who meet the recommended levels of PA and screen time remains low. Promotional efforts need to extend beyond school sports in Poland and multicomponent strategies that engage family, peers and the community should be encouraged in order to maximize participation in PA for Polish children and youth.

\section{References}

1. Mazur J. Health Behaviour of School Youth in Poland. Warsaw, Poland: Institute of Mother and Child; 2015. 
2. Mazur J, Oblacińska A, Jodkowska M, et al. Physical Activity of School Children Aged 9-17. Warsaw, Poland: Institute of Mother and Child; 2013.

3. Zembura P, Gołdys A, Nałẹcz H. Results from the Poland's 2016 report card on physical activity for children and youth. $J$ Phys Act Health. 2016;13(suppl 2):S237-S241. doi:10.1123/jpah.2016-0386

4. Downs SH, Black N. The feasibility of creating a checklist for the assessment of the methodological quality both of randomised and non-randomised studies of health care interventions. J Epidemiol Community Health. 1998;52(6):377-384. PubMed ID: 9764259. doi:10.1136/jech.52.6.377.

5. Lubowiecki-Vikuk A, Biernat E. Organized and unorganized forms of physical activity in leisure time among junior high school students in relation to individual and socio-environmental factors. Probl Hig Epidemiol. 2015;96(2):448-457.

6. Wojtyła-Buciora P, Bołdowski T, Wojtyła C, et al. An all-poland survey of physical activity and sedentary lifestyles for middle school, high school and university students. $J$ Health Inequalities. 2017;3(1):70-77. doi:10.5114/jhi.2017.69169
7. Tomkinson GR, Carver KD, Atkinson F, et al. European normative values for physical fitness in children and adolescents aged 917 years: results from 2779165 eurofit performances representing 30 countries. Br J Sports Med. 2017;51(21):1545-1554. doi:10.1136/ bjsports-2016-095987

8. Dobosz J, Mayorga-Vega D, Viciana J. Percentile values of physical fitness levels among polish children aged 7 to 19 years - a populationbased study. Cent Eur J Public Health. 2015;23(4):340-351. PubMed ID: 26841149. doi:10.21101/cejph.a4153.

9. Czyż SH, Toriola AL, Starościak W, Lewandowski M, Paul Y, Oyeyemi AL. Physical fitness, physical activity, sedentary behavior, or diet-what are the correlates of obesity in polish school children? Int J Environ Res Public Health. 2017;14(6):664. doi:10.3390/ ijerph14060664

10. Tabak I. The role of parents in supporting teenage children undertaking physical activity. Pediatr Pol. 2015;91(1):26-34. doi:10.1016/ j.pepo.2015.11.002

11. TNS Opinion \& Social. Special Eurobarometer 472 - December 2017 “Sport and Physical Activity”. European Commission; 2017. 